\title{
CONTROLE DE CONVENCIONALIDADE E ACESSO À JUSTIÇA: UMA ANÁLISE DO BENEFICIÁRIO DA JUSTIÇA GRATUITA A LUZ DA REFORMA TRABALHISTA
}

\author{
CONVENTIONALITY CONTROL AND ACCESS TO JUSTICE: AN ANALYSIS OF THE \\ BENEFICIARY OF FREE JUSTICE IN THE LIGHT OF LABOR REFORM
}

\section{CONTRÔLE DE LA CONVENTIONALITÉ ET ACCÈS À LA JUSTICE: UNE ANALYSE DU BÉNÉFICIAIRE DE LA JUSTICE LIBRE À LA LUMIÈRE DE LA RÉFORME DU TRAVAIL}

\begin{abstract}
Natalia Mascarenhas Simões Bentes Doutora em Direito Público, Universidade de Coimbra, Portugal Centro Universitário do Estado do Pará natalia.bentes@cesupa.br OrcidID: http://orcid.org/0000-0003-0163-2408
\end{abstract}

Vanessa Rocha Ferreira Doutora em Direitos Humanos, Universidade de Salamanca, Espanha Centro Universitário do Estado do Pará vanessarochaf@gmail.com OrcidID: http://orcid.org/0000-0001-5997-3198

Resumo: Texto se propõe a discutir a violação do direito de acesso à justiça a partir da análise da atual redação dos art. 790-B, 791-A e 844 da Consolidação das Leis do Trabalho (CLT), introduzidos no ordenamento jurídico brasileiro pela Lei $\mathrm{n}^{\circ} 13.467 / 17$, conhecida com a alcunha de Reforma Trabalhista. Tais dispositivos permitem que ocorra, em algumas situações, a condenação do beneficiário da justiça gratuita em custas processuais. Por meio de um estudo teórico-normativo, discute-se, por meio do método dedutivo, a inconvencionalidade desses novos dispositivos na medida em que violam frontalmente, não só a Constituição Federal, mas também convenções internacionais de direitos humanos.

Palavras-chave: Acesso à justiça. controle de convencionalidade. honorários advocatícios. justiça gratuita. 


\begin{abstract}
Text proposes to discuss the violation of the right of access to justice based on the analysis of the current wording of art. 790-B, 791-A and 844 of the Consolidation of Labor Laws (CLT), introduced in the Brazilian legal system by Law No. 13,467 / 17, known as the Labor Reform. Such provisions allow the beneficiary of free justice to be convicted in some situations in court costs. Through a theoretical-normative study, it is discussed, through the deductive method, the unconventionality of these new devices to the extent that they directly violate, not only the Federal Constitution, but also international human rights conventions.
\end{abstract}

Keywords: Access to justice. conventionality control. advocative hours. free justice.

Resumen: Le texte propose de discuter de la violation du droit d'accès à la justice sur la base de l'analyse du libellé actuel de l'art. 790-B, 791-A et 844 de la consolidation des lois du travail (CLT), introduites dans le système juridique brésilien par la loi ${ }^{\circ}{ }^{\circ} 13467 / 17$, connue sous le nom de réforme du travail. De telles dispositions permettent au bénéficiaire de la justice gratuite d'être condamné dans certaines situations au titre des frais de procédure. A travers une étude théorico-normative, il est discuté, par la méthode déductive, le caractère non conventionnel de ces nouveaux dispositifs dans la mesure où ils violent de front non seulement la Constitution fédérale, mais aussi les conventions internationales des droits de l'homme.

Palabras clave: Accès à la justice. contrôle de conventionalité. heures de plaidoyer. justice gratuite.

\title{
1 Introdução
}

Diversas foram as modificações introduzidas no ordenamento jurídico brasileiro pela Lei $\mathrm{n}^{\mathrm{o}}$ 13.467/2017, a chamada Reforma Trabalhista. Algumas dessas modificações são bastante polêmicas, especialmente por restringir, de certa maneira, o direito fundamental de acesso à Justiça, previsto no art. $5^{\circ}$, LXXXV da Constituição da República Federativa do Brasil (CRFB/88)

O presente estudo tem como objetivo central discutir a inconvencionalidade de alguns dispositivos que foram introduzidos na Consolidação das Leis do Trabalho (CLT) com a Reforma Trabalhista, especificamente os art. 790-B; 791-A, $\S 4^{\circ}$ e 844 , $\S 2^{\circ}$ que tratam da possibilidade da condenação do beneficiário da justiça gratuita em despesas processuais, dentre as quais custas processuais e honorários advocatícios sucumbenciais e periciais.

Portanto, se questiona se os art. 790-B; 791-A, $\S 4^{\circ}$ e 844 , $\S 2^{\circ}$ que introduziram mudanças no ordenamento jurídico brasileiro são incompatíveis com tratados internacionais de Direitos Humanos, em especial, a Convenção Americana de Direitos Humanos, de 1969 e com a jurisprudência da Corte Interamericana de Direitos Humanos. 
Para a elaboração deste artigo utilizou-se o método dedutivo, a partir da realização de pesquisa bibliográfica e documental, que busca suporte na legislação e na doutrina sobre o tema proposto.

$\mathrm{O}$ artigo encontra-se dividido em seis itens, sendo o primeiro esta introdução, o segundo que trata do direito de acesso à justiça como um direito fundamental; o terceiro que aborda a possível relativização do direito de acesso à justiça, especialmente para os beneficiários da justiça gratuita, o quarto item que por meio de um estudo interdisciplinar discute o controle de convencionalidade dos dispositivos analisados no artigo, o quinto item que trata da inconvencionalidade dos artigos 790-B, 791-A e 844, $\S 2^{\circ}$ da CLT, e por fim, o sexto e último item que apresenta as considerações das autoras sobre o estudo proposto.

\section{$2 \mathrm{O}$ Direito de acesso à justiça como um direito fundamental}

Essencial para garantir a eficácia de outros direitos fundamentais, o direito de acesso à justiça é extraído basicamente do princípio da inafastabilidade da jurisdição, previsto no art. $5^{\circ}$, XXXV da Constituição da República Federativa do Brasil (CRFB/88) como um direito fundamental, quando prevê que "a lei não excluirá da apreciação do Poder Judiciário lesão ou ameaça a direito".

Dessa forma, o Estado é incumbido da responsabilidade de solucionar eventuais demandas, fruto de litígios levados à sua apreciação, com a finalidade de pacificar demandas sociais. Assim, é assegurado a todo aquele que têm direitos violados, ou ameaça de lesão a direitos, a possibilidade de buscar a reparação por intermédio do Poder Judiciário.

$\mathrm{Na}$ verdade, consideração a vedação à autotutela, o direito de acesso à justiça não é conferido apenas quando a pretensão postulada em juízo é julgada procedente. Basta que o indivíduo se sinta lesado em um direito seu que já lhe é conferida a prerrogativa para instaurar processo judicial, ainda que, ao final, seu pedido seja rejeitado, o que, por si só, não lhe acarretará nenhuma penalidade, a não ser em casos de má-fé.

Fora isso, é importante mencionar que o acesso à justiça conta com outros dispositivos constitucionais que lhe complementam, como por exemplo dos direitos previstos no artigo $5^{\circ}$ da CRFB/88, como o direito de petição (inciso XXXIV, alínea "a") e o direito à assistência jurídica (inciso LXXIV).

No plano internacional, esse direito também encontra guarida no Artigo VIII, da Declaração Universal de Direitos Humanos (DUDH/1948), que prevê que todos "têm direito 
de receber dos tribunais nacionais competentes remédio efetivo para os atos que violem os direitos fundamentais que lhe sejam reconhecidos pela constituição ou pela lei”.

Assim, é possível perceber que se trata de uma garantia essencial para o exercício da cidadania, reconhecida não só no plano interno, mas também no plano internacional, e por isso, não pode ter a sua observância dificultada, especialmente em um Estado Democrático de Direito, como se declara o Brasil.

Acerca do conceito de acesso à justiça, Cappelletti reconhece que se trata de expressão de difícil definição, porém evidencia que ele serve para determinar duas finalidades básicas do ordenamento jurídico: a acessibilidade de todos e a justiça do resultado. Acompanhe:

A expressão "acesso à justiça" é reconhecidamente de difícil definição, mas serve para determinar duas finalidades básicas do sistema jurídico - o sistema pelo qual as pessoas podem reivindicar seus direitos e/ou resolver seus litígios sob os auspícios do Estado. Primeiro, o sistema deve ser igualmente acessível a todos; segundo, ele deve produzir resultados que sejam individual e socialmente justos. (CAPPELLETTI, 1988, p. 8)

Note-se que o que o supracitado doutrinador propõe é que o acesso à justiça seja efetivo para poder minimizar o desequilíbrio socioeconômico existente. Ou seja, é preciso que, além de se assegurar ao indivíduo o direito de ingressar em juízo quando sofre violação ou ameaça de violação a seus direitos, se assegurem condições concretas de efetivação de decisões socialmente justas.

Acerca do tema, Watanabe, Dinamarco e Grinover (1988, p.135) afirmam que para que o acesso à ordem jurídica seja justo e necessário que se observem quatro elementos:

1) o direito à informação e perfeito conhecimento do direito substancial orientada à aferição constante da adequação entre a ordem jurídica e a realidade socioeconômica do país;

2) direito de acesso à justiça adequadamente organizada e formada por juízes inseridos na realidade social e comprometidos com o objetivo de realização da ordem jurídica justa;

3) direito à preordenação dos instrumentos processuais capazes de promover a efetiva tutela de direitos; e, por derradeiro,

4) direito à remoção de todos os obstáculos que se anteponham ao acesso efetivo à Justiça com tais características.

Dessa forma, o acesso à justiça engloba vários aspectos processuais para sua efetiva concretização, como o direito à informação, a duração razoável do processo, etc.

Na Justiça do Trabalho Brasileira, o direito de acesso à justiça é elevado a um patamar bastante significativo. Nesta seara do judiciário, a estrutura institucional normativa 
criada prestigia o amplo acesso à ordem jurídica. Essa justiça especializada, que tem como finalidade precípua manter a relação laboral equilibrada, reconhecendo, para tanto, a hipossuficiência do trabalhador, possui princípios próprios voltados para a proteção desse litigante.

Para atingir a sua finalidade, alguns institutos também foram consagrados legalmente como por exemplo jus postulandi, que permite às partes, empregador e empregado, demandarem sem a necessidade de constituir advogado nos autos, nos termos do art. 791, da CLT. Também prevê, nos $\S \S 3^{\circ}$ e $4^{\circ}$ do art. 790, da CLT, o benefício da justiça gratuita, concedido a pedido ou de ofício, àqueles que não tiverem condições financeiras para arcar com custas processuais.

Essas ferramentas, adotadas na justiça do trabalho visam minimizar os empecilhos existentes ao acesso à justiça, eliminando uma das principais barreiras para que ele ocorra, que é justamente, como já mencionado, o desequilíbrio socioeconômico existente entre as partes, que muitas vezes impede que o indivíduo busque a tutela jurisdicional por causa dos altos custos que a demanda impõe para resguardar os seus direitos envolvidos.

Assim, por ser o direito de acesso à justiça uma garantia constitucional, o Estado não pode criar qualquer obstáculo que inviabilize a sua efetivação.

Perceba-se, portanto, que o direito de acesso efetivo e real à justiça engloba uma série de premissas, dentre elas, a garantia de poder postular em juízo sem a presença de um advogado, quando o empregado não tem condições de arcar com esse ônus, o direito de ser representado judicialmente pelo sindicato da categoria profissional (art. 592-A, II, a, da CLT), a inexigibilidade do pagamento de custas processuais quando impossível de ser arcado pela parte, e o direito de produzir os meios de prova necessários para comprovar suas alegações, como por exemplo, a prova pericial.

Desta forma, entende-se que o Estado deve criar mecanismos para assegurar o direito de acesso à justiça, não podendo impedir a correta efetivação.

\section{A reforma trabalhista e a relativização do acesso à justiça}

Como já mencionado anteriormente a Justiça do Trabalho tem por função institucional assegurar, dentre outras coisas, o pleno acesso ao judiciário, inclusive daquele que é hipossuficiente dentro de uma relação jurídica. Exatamente por isso que a justiça do trabalho sempre contou com institutos próprios, como por exemplo o jus postulandi, voltado a assegurar o acesso à justiça daquele que não tem condições de contratar um advogado. 
Fato é que, historicamente, essa área do judiciário sempre tentou minimizar os empecilhos existentes ao acesso à justiça, eliminando uma das principais barreiras para que ele ocorra, que é justamente o desequilíbrio socioeconômico existente entre as partes, que muitas vezes impede que o indivíduo busque a tutela jurisdicional por causa dos altos custos que a demanda impõe para resguardar os seus direitos envolvidos.

A Lei $\mathrm{n}^{\mathrm{o}}$ 13.467/17, usualmente conhecida como a Reforma Trabalhista, realizou diversas modificações no ordenamento jurídico brasileiro. Algumas dessas alterações causaram bastante polêmica e já foram, inclusive, questionadas judicialmente quanto a sua constitucionalidade, como por exemplo os arts. 790-B, 791-A e 844, § $2^{\circ}$ da CLT, que elevaram o custo do processo para as partes, pois passaram a prever novas regras que dificultam a concessão do benefício da justiça gratuita (como por exemplo, exigir a comprovação de hipossuficiência) e possibilitam a condenação do beneficiário da justiça gratuita ao pagamento de custas processuais quando o trabalhador faltar a audiência inaugural (Art. 791-A, $\S 4^{\circ}, \mathrm{CLT}$ ), e também a condenação em honorários periciais (Art. 790-B, CLT) e sucumbenciais (Art. 844, § $2^{\circ}$, CLT).

Tamanha a relevância constitucional acerca desse tema que a Procuradoria Geral da República (PGR), ajuizou perante o Supremo Tribunal Federal (STF) a Ação Direta de Inconstitucionalidade (ADI) $\mathrm{n}^{\mathrm{o}}$ 5766, em 25 de agosto de 2017, a fim de questionar a constitucionalidade desses dispositivos.

Anteriormente às alterações feitas na CLT, o beneficiário da justiça gratuita gozava de uma situação bastante diferenciada, pois não tinha que arcar com custas e despesas processuais, o que, de certo modo, estava em consonância com o que dispõe a Constituição Federal, no art. 5', LXXIV, ao prever que "O Estado prestará assistência jurídica integral e gratuita aos que comprovarem insuficiência de recursos" (BRASIL, 1988).

Note-se que tais modificações podem inviabilizar o acesso à justiça, na medida em que elevam os riscos econômicos do processo judicial trabalhista, fazendo com que o autor da demanda pondere os possíveis riscos de ajuizá-la, uma vez que poderá ser condenado a arcar com custas e despesas processuais.

Acerca do que dispõe o art. 791-A da CLT, em seu $\S 4^{\circ}$, ao prever a possibilidade de condenação do reclamante beneficiário da justiça gratuita aos honorários sucumbenciais, Maior e Valdete (2017, p. 81) destacam que:

Aqui talvez se esteja diante de uma das mais nefastas previsões da Lei n. ${ }^{\circ} 13.467 / 17$, pois a sucumbência recíproca é a antítese da razão de existência mesma de um processo do trabalho, ao menos nos moldes propostos, isto é, sem o reconhecimento da gratuidade como princípio 
do acesso à justiça e sem a concessão dos benefícios da assistência judiciária gratuita, ou seja, impondo custos a quem não tem como pagar. A Justiça do Trabalho tem por pressuposto a facilitação do acesso à justiça, o que inclui a noção de jus postulandi e de assistência gratuita.

Para Silva (2018, p. 1101) essas modificações são uma "inibição processual da fruição dos demais direitos sociais do trabalhador, por não permitir aos necessitados o acesso à justiça".

Notadamente, essa previsão cerceia ainda mais o acesso à justiça daquele que não tem condições de arcar com as despesas processuais. Assim, entende-se que essas inovações legislativas violam a ideia de efetivo direito de acesso à justiça, na medida em que dificultam a busca pela proteção aos direitos sociais trabalhistas.

\section{Controle de convencionalidade}

A expressão "controle de convencionalidade" historicamente foi desenvolvida pelo Conselho Constitucional Francês na Decisão 74-54 DC, de 15 de janeiro de 1975, que tratava da análise de constitucionalidade de uma lei que versava sobre a interrupção voluntária da gestação que violava o direito à vida assegurado no art. $2^{\circ}$ da Convenção Europeia de Direitos do Homem, ratificada e reconhecida pelo Estado Francês. O art. 61 da Constituição Francesa dispõe que as leis ordinárias, antes de sua aplicação, devem ser submetidas ao Conselho Constitucional, para verificação de adequação com o texto constitucional - controle de constitucionalidade. Bem como, o art. 55 da Constituição francesa afirma que os tratados e acordos ratificados têm, a partir de sua publicação, hierarquia superior às leis ordinárias, restando, desse modo, ao Conselho Constitucional Francês, a análise de dois tipos de controle normativo: a adequação da lei com a Constituição e a adequação da lei com os tratados e acordos internacionais, de hierarquia superior. Nessa oportunidade, o Conselho francês reconheceu a existência de dois modos distintos de controle normativo: o controle de constitucionalidade e o controle de convencionalidade. (CHAVES; SOUSA. 2016)

No âmbito do Sistema Interamericano de Proteção dos Direitos Humanos, o controle de convencionalidade consiste em:

Verificar la compatibilidad de las normas y demás prácticas internas con la $\mathrm{CADH}$, la jurisprudencia de la Corte IDH y los demás tratados interamericanos de los cuales el Estado sea parte; b) Es una obligación que corresponde a toda autoridad pública en el ámbito de sus competencias; c) Para efectos de determinar la compatibilidad con la CADH, no sólo se debe tomar en consideración el tratado, sino que también la jurisprudencia de la 
Corte IDH y los demás tratados interamericanos de los cuales el Estado sea parte; d) Es un control que debe ser realizado ex officio por toda autoridad pública; y e) Su ejecución puede implicar la supresión de normas contrarias a la $\mathrm{CADH}$ o bien su interpretación conforme a la $\mathrm{CADH}$, dependiendo de las facultades de cada autoridad pública. (CORTEIDH, 2019)

A Corte Interamericana entende que juízes e tribunais internos estão sujeitos ao Estado de Direito e, portanto, são obrigados a aplicar as disposições em vigor no sistema jurídico. Mas quando um Estado ratifica um tratado internacional como a Convenção Americana, seus juízes, como parte do aparato estatal, também ficam sujeitos a ela, o que os obriga a garantir que os efeitos das disposições da Convenção não sejam diminuídos por a aplicação de leis contrárias ao seu objeto e finalidade, e que desde o início não têm efeitos legais. Em outras palavras, o Judiciário deve exercer uma espécie de controle da convencionalidade entre as normas legais internas que se aplicam em casos específicos e a Convenção Americana sobre Direitos Humanos. Nessa tarefa, o Judiciário deve levar em conta não apenas o tratado, mas também a interpretação que a Corte Interamericana, o último intérprete da Convenção Americana, fez dele. (CORTEIDH, 2006)

Vale ressaltar que o controle de convencionalidade, assim como o controle de constitucionalidade, diz respeito às violações que ultrapassam o delimitado por leis e atos normativos. No controle de constitucionalidade, estes são analisados em face da Constituição Federal, ao passo que no controle de convencionalidade há um processo de compatibilização vertical das normas internas por Tratados Internacionais de Direitos Humanos.

$\mathrm{Na}$ jurisprudência da Corte Interamericana (Corte IDH) surgiu o conceito de controle de convencionalidade "para nomear a ferramenta que permite aos Estados especificar a obrigação de garantir os direitos humanos na esfera doméstica, através da verificação da conformidade das normas e práticas nacionais, com a Convenção Americana do Direito do Homem (CADH) e sua jurisprudência. (CIDH, 2019)

O controle de convencionalidade tem aplicação no âmbito nacional e internacional. No âmbito internacional, essa função é desempenhada pela Corte Interamericana e consiste na expulsão de regras contrárias à $\mathrm{CADH}$, com base nos casos específicos submetidos ao conhecimento do Tribunal. Isso aconteceu, por exemplo, com a declaração de incompatibilidade de leis de anistia com as obrigações impostas pela CADH. Esta função tem sido a principal da Corte Interamericana desde a sua entrada em operação, uma vez que a Corte Interamericana é responsável por interpretar a Convenção e revisar que os atos e atos dos Estados que tenham reconhecida sua competência, em conformidade com as disposições da CADH. 
Contudo, importante ressaltar o entendimento da tese de Mazzuoli (2016, p.423), que se mostra diverso do entendimento do STF. O mesmo defende que os tratados de Direitos Humanos possuem um nível constitucional, independente de sua aprovação como Emenda Constitucional, por observância do princípio pro hominie, o qual preza pela aplicação da norma mais favorável ao ser humano independentemente da aprovação legislativa por maioria qualificada.

No caso Almonacid Arellano y Otros versus Chile de 2006 (CORTEIDH,2006) o juiz Cançado Trindade ao analisar sobre a lei de Anistia, responsável por perdoar crimes cometido no período da ditadura militar chilena, fixou que as verdadeiras leis não podem ser arbitrárias nem considerar uma lei como sendo superior a outras - devem ser abstratas e incorporar princípios que as informem e conformem. As leis devem ser inspiradas pela ideia de Direito e pela busca do bem comum. Por descumprir todos esses quesitos, um ato que institui uma autoanistia não é verdadeiramente uma lei, ou seja, os Estados não podem emitir leis para conceder a anistia de crimes internacionais, como tortura, homicídios e desaparecimentos forçados.

A Corte reconhece a importância dos tribunais nacionais como protetores de Direitos constitucionais e fundamentais, mas a Convenção Americana não impõe um modelo específico para o controle da constitucionalidade e da convencionalidade. Nesse sentido, a Corte recorda que a obrigação de exercer um controle de convencionalidade entre normas internas e a Convenção Americana é de responsabilidade de todos os órgãos do Estado, inclusive de seus juízes e outros órgãos relacionados à administração da justiça em todos os níveis (CORTEIDH, 2014).

O controle de convencionalidade decorre dos princípios do direito internacional público, a exemplo do princípio da pacta sunt servanda, consagrado na Convenção de Viena sobre o Direito dos Tratados de 1969 (artigo 26), que reflete a obrigação de os Estados cumprirem os tratados dos quais fazem parte e o compromisso que os Estados que assinaram a Convenção Americana de Direitos Humanos têm que realizar um controle de convencionalidade para cumprir o mandato de proteção dos direitos fundamentais. Esse imperativo do direito internacional público deve ser cumprido de boa fé pelos Estados. A Convenção de Viena no artigo 27 explicita que os Estados não podem invocar disposições do direito interno para o não cumprimento de compromissos internacionais. Nesse sentido, a Corte Interamericana reafirmou que a obrigação de tomar todas as medidas necessárias para usufruir plena e efetivamente os direitos e liberdades consagrados na Convenção inclui a de adaptar os regulamentos não convencionais existentes. Nesse sentido, o controle da 
convencionalidade tem sólidos fundamentos jurídicos nas normas convencionais e nas normas e princípios do direito internacional público (CORTEIDH,2019).

Os principais entendimentos sobre o controle de convencionalidade consiste na verificação da compatibilidade das normas e outras práticas internas com a Convenção Americana $(\mathrm{CADH})$, com a jurisprudência da Corte Interamericana e os demais tratados interamericanos dos quais o Estado é parte. Deve ser realizado de ofício por todas as autoridades públicas. O seu exercício é realizado no âmbito de cada autoridade, portanto, sua execução pode implicar a supressão de normas contrárias ao CADH ou sua interpretação de acordo com o CADH. (CORTEIDH, 2019)

Portanto, vale salientar que todo e qualquer tratado de Direitos Humanos é paradigma para o controle de convencionalidade, conforme redação dada ao artigo $64, \S 1^{\circ}$ da Convenção Americana (MAZZUOLI, 2016, p. 424).

No Brasil, temos duas modalidades de controle de convencionalidade: o controle concentrado e o controle difuso. O controle concentrado de convencionalidade visa solucionar o modo de operacionalização perante o STF, além de buscar uma base jurídica para exercê-lo perante a Corte. Sendo assim, entende-se que apenas os instrumentos de direitos humanos equivalentes a emendas constitucionais, ou seja, os aprovados pela maioria em três quintos dos votos dos membros de cada casa do Congresso Nacional - podem ser paradigma a esse modo de controle de convencionalidade perante o STF, pois possuem status material e formal de norma constitucional (MAZZUOLI, 2016, p. 430).

Já no controle difuso de convencionalidade o objeto de controle serão os Tratados de Direitos Humanos que não foram internalizados como emendas constitucionais, mas que são ratificados e estão em vigor no plano interno. Conforme o artigo $5^{\circ}, \S 2^{\circ}$, da $\mathrm{CRFB} / 88$, eles já possuem status material de norma constitucional. Esse controle pode ser exercido por todos os juízes e tribunais do país, a requerimento das partes ou ex officio. Uma vez que todos os tratados de Direitos Humanos em vigor no Brasil guardam nível materialmente constitucional (MAZZUOLI, 2016, p. 430).

Também, segundo a CORTEIDH, a obrigação que está sempre presente após o controle da convencionalidade é realizar um exercício hermenêutico que compatibilize as obrigações do Estado com seus regulamentos internos. Importante ressaltar que os regulamentos internacionais e a jurisprudência da Corte Interamericana, tanto contenciosos quanto consultivos, são uma escala de convencionalidade. Por fim, a obrigação de realizar o controle deriva dos princípios do direito internacional público e das obrigações internacionais 
do próprio Estado assumidas no momento de fazer parte da Convenção Americana sobre Direitos Humanos. (CORTEIDH, 2019).

Cançado Trindade, seguindo Gustav Radbruch e confrontando os efeitos maléficos do positivismo, defende a existência de princípios fundamentais do direito que são mais fortes que todo e qualquer preceito jurídico positivo, as normas imperativas de direito internacional, jus cogens. Assim, a lei que os violem fica desprovida de validade. As autoanistias negam o Direito, por negarem o acesso à justiça, à igualdade perante a lei e o direito ao juiz natural. No citado caso, Trindade reconhece o caráter de direito jus cogens ao "acesso à justiça" para a responsabilidade internacional de crimes no período da ditatura e, por via consequencial, dessas normas de anistia que violam o Estado de Direito. O juiz expõe que os Estados não podem usar de artifícios para violar o jus cogens (como as "leis" de autoanistia), pois essas normas não dependem do consentimento estatal para obrigarem. E mais, o jus cogens ultrapassa o direito dos tratados, englobando o Direito Internacional em geral.

Outros casos reforçam a ideia de que o acesso à justiça constitui um direito jus cogens, ou seja, uma norma imperativa de direito internacional, em particular à necessidade de avançar na construção jurisprudencial do Tribunal, no sentido de expansão do conteúdo material do jus cogens (de modo a cobrir também o direito de acesso à justiça lato sensu), bem como o reconhecimento das obrigações de resultado e não apenas de meio, como no “Caso Baldeón García versus Perú”, “Goiburú y Otros versus Paraguay” e "Masacre de Pueblo Bello versus Colombia” (CORTEIDH, 2006).

No âmbito de abrangência das normas imperativas de direito internacional vem sendo ampliado progressivamente. A Corte Interamericana de Direitos Humanos, direta e indiretamente vem prevendo diversos direitos como vinculantes, independentemente do consentimento estatal, em especial o acesso à justiça. Assim, Cançado Trindade defende que o direito emana da consciência comum do que é juridicamente necessário e a consciência jurídica universal é o reconhecimento das normas de direito internacional como caráter de jus cogens (TRINDADE, 2006).

É bem verdade que, por um lado, a noção de uma "ordem pública internacional", formada por normas dispositivas e imperativas (jus cogens), ainda é embrionária e imperfeita, dependendo do desenvolvimento de uma teoria das normas de Direito Internacional, contudo, é inegável a força imperativa do acesso à justiça no âmbito mundial.

Contudo, os avanços trazidos na promoção dos Direitos Humanos e na sua proteção por meio da responsabilização internacional dos Estados demonstram o anseio e a necessidade da Comunidade Internacional na confirmação do caráter impositivo de determinadas normas e 
direitos. $\mathrm{O}$ entendimento de que o acesso à justiça são normas jus cogens reforça a estruturação do controle de convencionalidade e da responsabilidade internacional do Estado que não adeque seu ordenamento interno ao ordenamento internacional. As normas jus cogens, então, servem como pauta axiológica, oferecendo substrato ético para a atuação dos Estados e, ao mesmo tempo, servindo de instrumento de controle da ação estatal e de responsabilização internacional.

Também, diante da aceitação do princípio da indivisibilidade dos Direitos Humanos consagrado na Conferência Mundial de Viena sobre Direitos Humanos de 1993, houve o alargamento do conceito de obrigação internacional erga omnes no campo dos direitos humanos. Dessa forma, deixa mais evidente o interesse jurídico da comunidade internacional na proteção de todos os direitos humanos internacionalmente reconhecidos, dentre eles, o acesso à justiça, inclusive aos mais vulneráveis.

\section{A inconvencionalidade dos artigos $790-\mathrm{B}, 791-\mathrm{A} \S 4^{\circ}$ e $884, \S 2^{\circ}$ da CLT}

Como já mencionado, a Reforma Trabalhista passou a prever novas regras para os beneficiários da Justiça Gratuita na seara laboral. Antes de adentrarmos na inconvencionalidade das mudanças, convém mencioná-las para que o objetivo do presente texto seja alcançado.

Primeiramente o novo art. 790-B, da CLT passou a prever a possibilidade de o beneficiário da justiça gratuita pagar honorários periciais quando sucumbente na pretensão objeto da perícia. Observe-se que esse dispositivo pode inibir o requerimento para a produção de prova pericial, violando o acesso à jurisdição e afrontando diretamente o art. $5^{\circ}$, LXXIV da CRFB/88 que prevê que o estado deve conceder assistência jurídica gratuita aos que comprovarem insuficiência de recursos (KOURY, 2018, 1060).

$\mathrm{O}$ art. 791-A da CLT passou a prever o cabimento de honorários advocatícios sucumbenciais na justiça do trabalho, que serão fixados entre o "mínimo de 5\% (cinco por cento) e o máximo de $15 \%$ (quinze por cento) sobre o valor que resultar da liquidação da sentença, do proveito econômico obtido ou, não sendo possível mensurá-lo, sobre o valor atualizado da causa". (CLT, 1943).

Esses honorários serão devidos ao advogado da parte reclamante que tem seus pedidos procedentes ou, ao advogado da reclamada que tenha obtido êxito em algum ou em todos os pedidos feitos pela parte reclamante, independentemente de serem beneficiários da justiça gratuita. A legislação atual admite, ainda, que o valor devido pelo reclamante possa ser 
buscado inclusive em outro processo em que ele tenha verbas a receber, nos termos do $\S 4^{\circ}$ do art. 791-A, CLT.

$\mathrm{O}$ art. $844, \S 2^{\circ}$ da CLT que também trouxe uma inovação prejudicial ao reclamante beneficiário da justiça gratuita ao prever que caso ele falte na audiência inaugural, será condenado ao pagamento de custas processuais, sendo esse pagamento condição indispensável para a propositura de nova demanda.

Todas essas previsões limitam o direito de acesso à justiça daquele que não tem condições de arcar com as custas e despesas processuais, na medida em que dificultam a busca pela proteção aos direitos sociais trabalhistas. E por conseguinte, violam diretamente a previsão constitucional do acesso à justiça e da assistência jurídica gratuita e integral.

No que tange ao controle de convencionalidade, é possível a propositura de ação que questione a inconstitucionalidade e inconvencionalidade do art. 790-B, pois está em desacordo com art. $5^{\circ} \S 2^{\circ}$ da CRFB/88 que dispõe que os direitos e garantias expressos nesta Constituição não excluem outros decorrentes do regime e dos princípios por ela adotados, ou dos tratados internacionais em que a República Federativa do Brasil seja parte. No âmbito da inconvencionalidade, dentre as convenções que o Brasil é parte e trata sobre o acesso à justiça, podemos citar a Declaração Universal dos Direitos Humanos, no artigo $8^{\circ}$ que define que toda a pessoa tem direito a recurso efetivo para as jurisdições nacionais competentes contra os atos que violem os direitos fundamentais reconhecidos pela Constituição ou pela lei. Bem como o artigo $10^{\circ}$, em que toda a pessoa tem direito, em plena igualdade, a que a sua causa seja equitativa e publicamente julgada por um tribunal independente e imparcial que decida dos seus direitos e obrigações ou das razões de qualquer acusação em matéria penal que contra ela seja deduzida.

Bem como o artigo 14 do Pacto de Direitos Civis e Políticos de 1966, ratificado pelo Decreto $n^{\circ} 592$ de 1992, dispõe que todas as pessoas são iguais perante os tribunais e as cortes de justiça, assim, toda pessoa terá o direito de ser ouvida publicamente e com as devidas garantias por um tribunal competente, independente e imparcial, estabelecido por lei, na apuração de qualquer acusação de caráter penal formulada contra ela ou na determinação de seus direitos e obrigações de caráter civil.

Por fim, o artigo 8 da Convenção Americana de Direitos Humanos que define as garantias judiciais:

Toda pessoa tem direito a ser ouvida, com as devidas garantias e dentro de um prazo razoável, por um juiz ou tribunal competente, independente e imparcial, estabelecido anteriormente por lei, na apuração de qualquer acusação penal formulada contra ela, ou para que se determinem seus 
direitos ou obrigações de natureza civil, trabalhista, fiscal ou de qualquer outra natureza. dispõe:

Bem como, o artigo 25 da Convenção Americana que trata sobre proteção judicial

Toda pessoa tem direito a um recurso simples e rápido ou a qualquer outro recurso efetivo, perante os juízes ou tribunais competentes, que a proteja contra atos que violem seus direitos fundamentais reconhecidos pela constituição, pela lei ou pela presente Convenção, mesmo quando tal violação seja cometida por pessoas que estejam atuando no exercício de suas funções oficiais.

Em sendo assim, esses tratados internacionais sobre direitos humanos, ratificados e vigentes no Brasil, não sendo aprovados por um quórum qualificado, possuem um status normativo supralegal, servindo como paradigma para o controle difuso de convencionalidade, conforme entendimento do Supremo Tribunal Federal, no RE de número 466.343-SP (STF, 2010). Isto quer dizer que tais tratados e convenções estão abaixo da Constituição Federal e acima das leis ordinárias e complementares, ou seja, podem servir de parâmetro para declaração de inconstitucionalidade e inconvencionalidade dos artigos 790-B, 791-A, $\S 4^{\circ}$ e $884, \S 2^{\circ}$ da CLT.

\section{Conclusão}

Conforme demonstrado acima, o direito de acesso à justiça é um direito fundamental, motivo pelo qual não pode sofrer maiores obstáculos para a sua efetivação.

A esse respeito, atribuir ao beneficiário da justiça gratuita um elevado ônus processual, ao possibilitar, por exemplo a condenação em honorários advocatícios de sucumbência e honorários periciais, a Lei $\mathrm{n}^{\mathrm{o}} 13.467 / 2017$ incorreu ao mesmo tempo em inconstitucionalidade, ao afrontar o que dispõe o art. $5^{\circ}$, incisos LXXIV e LXXXV da CRFB/88, e em inconvencionalidade ao afrontar a Declaração Universal dos Direitos Humanos de 1948, Pacto de Direitos Civis e Políticos de 1966 e a Convenção Americana de Direitos Humanos de 1969.

É evidente que na medida em que a legislação trabalhista prevê a possibilidade de despesas processuais aos beneficiários da justiça gratuita, cria nele o temor em judicializar uma demanda, ante os riscos de sair devedor de seu ex-empregador, tendo que arcar com uma despesa incompatível com sua condição financeira.

Até mesmo porque, em toda a ação judicial existe a possibilidade de vitória ou derrota, e o pagamento da verba honorária de sucumbência deve ser imposta somente àqueles que 
possuem condições financeiras de arcar com esta despesa sem prejuízo do sustento próprio ou de sua família.

$\mathrm{Na}$ hipótese de o trabalhador ser considerado pobre na forma da lei, não se mostra razoável a possibilidade de sua condenação ao pagamento de despesas processuais. O temor a essa condenação constituiu um obstáculo desarrazoado para concretização do direito fundamental de acesso à justiça, motivo pelo qual se defende a inconvencionalidade das modificações introduzidas no ordenamento jurídico brasileiro com o advento da Lei $\mathrm{n}^{\mathrm{o}}$ $13.467 / 17$.

Dessa forma, conclui-se que apesar de imprescindível na aplicação de normas de Direitos Humanos, o controle de convencionalidade no Brasil mostra-se coadjuvante frente ao controle interno já oferecido pela Constituição Federal de 1988.

O princípio do acesso à justiça deve fundamentar todas as ações do poder estatal, em qualquer uma de suas manifestações, inclusive, do poder legislativo, pois estão relacionados ao respeito e à garantia dos Direitos Humanos. Evidencia-se que esse princípio pode efetivamente ser considerado um imperativo do direito internacional geral por se aplicar a qualquer Estado, independentemente de ser ou não parte do tratado internacional, além de gerar efeitos em relação a terceiros, inclusive indivíduos.

Dessa forma, isso implica no fato de que o Estado, em seu sistema interno, por atos de qualquer de seus poderes ou de terceiros agindo sob sua tolerância, aquiescência ou negligência, não pode agir contra o princípio do acesso à justiça. Portanto, entende-se por inconstitucionais e inconvencionais os artigos 790-B, 791-A, $\S 4^{\circ}$ e 884, $\S 2^{\circ}$ da CLT.

\section{Referências}

CAPPELLETTI, Mauro. Acesso à justiça. Tradução de Ellen Graie Northfleet. Porto Alegre. Fabris. 1988.

CHAVES; SOUSA. Revista da Faculdade de Direito - UFPR, Curitiba, vol. 61, n. 1, jan./abr., p. 87-113, 2016.

CORTE IDH. Cuadernillo de Jurisprudencia de la Corte Interamericana de Derechos Humanos no 7, 2019. Disponível em: http://www.corteidh.or.cr/. Acesso em: 14 abr. 2020.

Corte IDH. Caso Almonacid Arellano y otros Vs. Chile. Excepciones Preliminares, Fondo, Reparaciones y Costas. Sentencia de 26 de septiembre de 2006. Serie C No. 154. Disponível em: http://www.corteidh.or.cr/. Acesso em: 12 abr. 2020. 
Corte IDH. Caso de la Masacre de Pueblo Bello Vs. Colombia. Fondo, Reparaciones y Costas. Sentencia de 31 de enero de 2006. Serie C No. 140. Disponível em: http://www.corteidh.or.cr/. Acesso em: 08 abr. 2020.

Corte IDH. Caso Baldeón García Vs. Perú. Fondo, Reparaciones y Costas. Sentencia de 6 de abril de 2006. Corte IDH. Caso Goiburú y otros Vs. Paraguay. Fondo, Reparaciones y Costas. Sentencia de 22 de septiembre de 2006. Serie C No. 153. Disponível em: http://www.corteidh.or.cr/. Acesso em: 14 abr. 2020.

CORTEIDH. Caso La Cantuta Vs. Perú. Fondo, Reparaciones y Costas. Sentencia de 29 de noviembre de 2006, párr.1732. Disponível em: http://www.corteidh.or.cr/. Acesso em: 15 de abril de 2020.

CORTEIDH. Caso Liakat Ali Alibux Vs. Suriname. Excepciones Preliminares, Fondo, Reparaciones y Costas. Sentencia de 30 de enero de 2014. Disponível em: http://www.corteidh.or.cr/. Acesso em: 12 abr. 2020.

KOURY, Luiz Ronan Neves; ASSUNÇÃO, Carolina Silva Silvino. A gratuidade da justiça no processo do trabalho: reflexões à luz do CPC e da Lei $n^{o}$ 13.467/17. In: A Reforma trabalhista e seus impactos. Salvador: Editora Jus Podivm, 2018, p. 1057-1074.

MAZZUOLI, Valério de Oliveira. Curso de Direito Internacional Público. V.10. Ed. São Paulo: Revista dos Tribunais, 2016.

SILVA, Sandoval Alves. O (in)acesso à Justiça social com a demolidora reforma trabalhista. In: A Reforma trabalhista e seus impactos. Salvador: Editora Jus Podivm, 2018, p. 10751103 .

SOUTO MAIOR, Jorge Luiz; SEVERO, Valdete Souto. $O$ acesso à justiça sob a mira da reforma trabalhista: ou como garantir o acesso à justiça diante da reforma trabalhista. In: Revista eletrônica [do] Tribunal Regional do Trabalho da $9^{a}$ Região. Curitiba, PR, v. 6, n. 61, 2017, p. 57-92.

SUPREMO TRIBUNAL FEDERAL. RECURSO EXTRAORDINÁRIO: 466343 SP, Relator: Min. CEZAR PELUSO, Data de Julgamento: 03/12/2008, Tribunal Pleno, Data de Publicação: DJe-104 DIVULG 04-06-2009 PUBLIC 05-06-2009 EMENT VOL-02363-06 PP-01106 RDECTRAB v. 17, n. 186, 2010, p. 29-165)

TRINDADE, Antônio Augusto Cançado. A Humanização do Direito Internacional. Belo Horizonte: Del Rey, 2006, p. 87-89. 